\title{
Current trends in aortic valve-preserving surgery
}

\author{
Takashi Kunihara ${ }^{1}$ \\ ${ }^{1}$ Jikei University School of Medicine
}

June 24, 2020

\begin{abstract}
The natural history of patients with aortic regurgitation (AR) is not as benign as once believed, even in asymptomatic patients with preserved left ventricular function. Aortic valve surgery can prolong survival of these patients. However, both mechanical and biological aortic valve replacement have major disadvantages, especially in young patients. Aortic valve-preserving surgery (AVP) has attracted a great deal of attention as it has significant survival benefit over replacement. Nonetheless, AVP has not been widely adopted due to the complexity of its technique and assessment (i.e., long learning curve). With recent technical and theoretical advances, AVP has increasingly been performed with better outcomes, and therefore earlier indication for surgical intervention in cases of AR has been considered. Recent advances in AVP include repair-oriented classification of the etiology of AR, objective assessment of the cusp configuration (i.e., effective height and geometric height), use of aortic annuloplasty, introduction of two reproducible valve-sparing root replacement procedures (i.e., aortic valve reimplantation and aortic root remodeling techniques), standardization of AVP, and assessment of cusp configuration with aortoscopy. A number of prospective multicenter studies are currently underway and will clarify the role of AVP in surgical treatment of AR in the near future.
\end{abstract}

\section{Natural history of patients with aortic regurgitation}

Studies of patient survival have shown that aortic regurgitation (AR) has a less benign course than once believed. In early series, the mortality rate was reported to be $\sim 0.2 \%$ annually. However, this was due to inadequate follow-up of the patients and this has increased to $2.2 \%$ per year based on recent studies with meticulous follow-up ${ }^{1-3}$. An elaborate study from the Cleveland Clinic reported that $29 \%$ of patients with grade III or greater AR and preserved left ventricular ejection fraction (LVEF) died without aortic valve surgery during a mean follow-up of $6.6 \pm 3$ years, whereas only $13 \%$ died following aortic valve surgery, which seemed similar to the survival of the age- and sex-matched population in the USA (Fig. 1) ${ }^{3}$. Other drawbacks of previous studies were low mortality rates of young patients which seemed unlikely in general clinical practice or lack of standardized assessment of AR severity. Another study from the Mayo clinic employed quantitative American Society of Echocardiography thresholds for AR grading ${ }^{4}$ and followed up the long-term prognosis of asymptomatic patients with LVEF [?] $50 \%$ and an average age of 60 years. They found that 10-year survival of overall patients and those aged 50 or more with severe AR was $69 \%$ and $59 \%$, respectively ${ }^{2}$.

\section{Impact of aortic valve preservation}

Aortic valve replacement (AVR) may be considered to treat AR in such cohorts. However, implantation of a prosthetic valve has a negative impact on long-term prognosis, especially in young patients. A recent metaanalysis revealed rates of structural valve deterioration and reintervention of $1.59 \%$ and $1.82 \%$ annually in a relatively young cohort $(50.7+-11.0$ years old $)$ undergoing bioprosthetic $\mathrm{AVR}^{5}$. For patients aged 
25 or 35 years old, lifetime risk of reintervention due to structural valve deterioration of the bioprosthesis was almost $100 \%$, and therefore life expectancy in this population was less than two thirds of that in the age- and sex-matched general population ${ }^{5}$. On the other hand, aortic root replacement with a mechanical composite graft was associated with an increased risk of thromboembolic events $(0.7 \%$ year $)$ compared with valve-sparing root replacement (VSRR) $(0.3 \% / \text { year })^{6}$. Accordingly, aortic root replacements using the both biological and mechanical composite graft were associated with increased major adverse valve-related events compared with VSRR (hazard ratio: 3.4 and 5.2, respectively) ${ }^{7}$.

Therefore, pioneers in aortic valve-preserving surgery (AVP) have recently reported that patients who had undergone AVP had significant survival benefit over those undergoing AVR (Fig. 2) ${ }^{7,8}$. In addition, due to recent advances in AVP, the reintervention rate has become comparable with AVR, and better than bioprosthetic AVR in younger populations (Fig. 3) ${ }^{7,8}$. Therefore, AVP has attracted increasing attention over the last decade.

\section{Current status of aortic valve-preserving surgery}

However, AVP is a less common procedure than mitral valvuloplasty (MVP) at the general community level. With regard to aortic valve procedures for AR, AVP was performed in only $1.7 \%$ of cases in Europe in $2001^{9}$ and $8 \%$ of cases in Japan in $2014^{10}$. A literature search for only aortic root procedures indicated that VSRR had been performed in $14 \%$ of cases in the USA from 2004 to early 2010 (the Society of Thoracic Surgeons database study) ${ }^{11}$ and $34 \%$ in Japan in 2014 (our original nationwide questionnaire) ${ }^{10}$. According to the Japan Cardiovascular Surgery Database, the ratio of VSRR among elective aortic root procedures performed for non-redo cases of AR in Japan increased to $45 \%$ in $2017^{12}$. Surprisingly, the in-hospital mortality rate after VSRR was only $0.7 \%$, whereas it increased to $2.8 \%$ after composite valve graft replacement (even among matched groups, the rates were $0.8 \%$ and $1.8 \%$, respectively $)^{12}$. So, Japanese surgeons may be not only aggressive but also have the excellent outcomes in VSRR.

\section{Why is aortic valve-preserving surgery not popular?}

One reason why surgeons have been reluctant to perform AVP may involve the conservative nature of the guidelines over the last decade. The current guidelines specify AVR as the standard surgical option in cases of AR. Therefore, they recommend aortic valve surgery in symptomatic patients or those with reduced left ventricular function as a class I indication ${ }^{13}{ }^{14}$. However, cases with depressed left ventricular function or advanced symptom are known to be associated with elevated mortality even after AVR ${ }^{15,16}$. In addition, when AVP is planned, better quality of repair can be anticipated before degeneration of the aortic cusps.

Of course, some researchers recognized these concerns and proposed earlier indication for surgical intervention. The Mayo clinic reported that patients with indexed left ventricular endosystolic dimension (LVESD) [?] $20 \mathrm{~mm} / \mathrm{m}^{2}$ had poorer survival at 10 years compared to those with indexed LVESD $<20 \mathrm{~mm} / \mathrm{m}^{2}$ (Fig. $4 \mathrm{~A})^{17}$. The Cleveland clinic also reported that patients with indexed LVESD between 20 and $25 \mathrm{~mm} / \mathrm{m}^{2}$ had a survival benefit after AVR compared to those without $\mathrm{AVR}^{3}$. Patients with LVEF [?] $50 \%$ but < $55 \%$ were reported to have poorer survival at 10 years compared to those with LVEF [?] $55 \%$ (Fig. $4 \mathrm{~B})^{18}$. Even after AVR, patients treated in accordance with the guidelines for earlier surgery showed better survival than those undergoing later operation ${ }^{19}$. Therefore, the latest Japanese guidelines recommend aortic valve surgery in patients with LVESD > $45 \mathrm{~mm}$ as a class IIa indication, taking Japanese body size into account (English version will be available soon).

Another reason may be complexity of AVP. Compared with the mitral valve, the aortic valve has smaller cusp volume, thinner cusp thickness, and three coaptation planes ${ }^{20}$. There are many technical alternatives for MVP, whereas there is no chordal replacement technique in AVP. Thus, a long learning curve of approximately $40-60$ cases is estimated for AVP, which has made this a technique exclusively for experienced surgeons ${ }^{21}$. 
Several technical/theoretical modifications or refinements have been made to increase adoption of AVP, which will be introduced in the following section.

\section{Advances in aortic valve-preserving surgery}

\section{Classification of the etiology of AR}

Previously, surgeons did not have a good understanding of the pathophysiology of AR. In 2009, classification of the etiology of AR was proposed by the Brussels group following Carpentier's classification of the etiology of mitral regurgitation (Fig. 5) ${ }^{22}$. Heart teams then had a common language resulting in a better understanding of the pathophysiology of AR, which appears beneficial in improving the outcome of $\mathrm{AVP}^{23}$. The varied phenotypes of bicuspid aortic valve (BAV) have complicated further understanding of the pathophysiology of AR. Although widely used, Sievers' classification of BAV phenotype is an anatomical classification according to the number of raphe $(0-2)$ and is not practical for AVP (Fig. 6A $)^{24}$. The Brussels and Homburg groups recently proposed a repair-oriented classification system based on the commissure angle (Fig. $6 \mathrm{~B})^{25}$. This is also anticipated to improve the outcome of AVP for BAV.

\section{Objective assessment of cusp configuration}

The post-repair cusp configuration had traditionally been assessed subjectively (i.e., by eyeballing). In 2006, Schafers advocated measuring the height difference between the central free margins and the aortic insertion lines using a dedicated caliper (i.e., effective height) (Fig. 7) ${ }^{26}$. This novel concept has made assessment of the cusp configuration more objective and reproducible. Lansac and colleagues reported that systematic cusp effective height assessment was associated with not only an increased rate of AVP but also improvement of repair durability ${ }^{27}$. In 2013, Schafers published the normal dimensions of human cusps, in particular the cusp height (i.e., geometric height) ${ }^{28}$. They defined retraction in adults as a geometric height [?] $16 \mathrm{~mm}$ in tricuspid aortic valves and [?] $19 \mathrm{~mm}$ in the BAVs, and recommended avoiding AVP in such cases. This concept has served as a useful basis for decision making in AVP. Recently, Komiya and colleagues suggested that patients with a small cusp size (geometric height $<16 \mathrm{~mm}$ ) can be candidates for AVP by tight annuloplasty because these cases have "annulus cusp mismatch" ${ }^{29}$. However, cases with severe mismatch may not be appropriate candidates for AVP. They also emphasized that annular size reduction may be mandatory even in cases with large cusps when "annulus cusp mismatch" exists.

\section{Advent of aortic annuloplasty}

The most distinct difference between MVP and AVP had been the availability of annuloplasty in the former. In 1958, Taylor and colleagues performed external suture annuloplasty for 11 beating hearts. However, this technique was not widely adopted due to unfavorable outcomes ${ }^{30}$. In 1966, Cabrol and associates proposed subcommissural annuloplasty, which was widely adopted because of its simplicity ${ }^{31}$. However, inhomogeneous plication negatively affects cusp movement and emerged as a risk of recurrence ${ }^{32}$. Circular annuloplasty procedures, such as external suture annuloplasty ${ }^{33}$, external ring annuloplasty ${ }^{27}$, and internal ring annuloplasty ${ }^{34}$, have been applied clinically in experienced centers, and appear to improve clinical outcomes of AVP (Fig. 8). Please refer to another systematic review article for many other alternatives ${ }^{35}$.

\section{Valve-sparing root replacement}

Two innovative approaches were developed to treat aortic root enlargement with or without AR; David and Feindel proposed reimplantation of the aortic valve (hereinafter referred to as reimplantation) in $1992^{36}$ and Sarsam and Yacoub advocated remodeling of the aortic root (hereinafter referred to as remodeling) in 1993 (Fig. 9) ${ }^{37}$. Then, valve stability after VSRR has improved dramatically and selection of VSRR among 
aortic root surgery procedures has become more common, as described before. The two approaches had both advantages and disadvantages, but they have been improved by a number of modifications ${ }^{38-40}$. Currently, reimplantation using a vascular prosthesis with neosinuses and remodeling with annuloplasty have become standard procedures and achieved reproducible outcomes ${ }^{27,41,42 .}$

Standardization of aortic valve-preserving surgery

Due to the long learning curve, as mentioned above, standardization of AVP has been attempted. Lansac pioneered the standardized approach for VSRR using a graft with neosinuses for remodeling because it was originally designed to perform remodeling operation (Fig. 8B) ${ }^{43}$. It sets three commissures at the same height and symmetric angle, and thus has less risk of distorting valve geometry. It was emphasized, however, that resultant discrepancy of effective height of each cusp should be aggressively corrected for better cusp durability, as described above ${ }^{27}$. He launched a multicenter study of remodeling, and thus the quality of AVP should be reproducible between institutions ${ }^{44,45}$.

His group also clarified that additional stabilization of the sinotubular junction (STJ) (i.e., double ring annuloplasty) is associated with better outcome compared to single external ring annuloplasty. They also intended to standardize this approach by indicating criteria for choice of the both ring sizes ${ }^{46}$. They recommended the same ring size for the annulus and STJ. In general, postoperative annulus diameter becomes smaller than external ring size because of the ventricular muscle thickness $(3.3-6.2 \mathrm{~mm})^{47}$. Recent echocardiographic analyses indicated that the ratio of annulus diameter to STJ diameter in normal subjects is approximately 1:1.1 - 1:1.2 $2^{48}$. Therefore, their standardized approach may restore normal root geometry.

Another experienced center selected a tube graft for remodeling automatically according to the body surface area of the patient followed by annuloplasty for one size smaller than the graft size, which will also create a reasonable root configuration ${ }^{42}$. For reimplantation, the Brussels group chose a graft with neosinuses corresponding to the commissure height between the left and non-coronary sinus, because commissure height remains relatively constant ${ }^{49}$.

We have also made efforts to standardize remodeling techniques ${ }^{50}$. We set the target annulus diameter based on the average annulus diameter for each body surface area ${ }^{51}$ and choose a one-size larger tube graft. Each scallop of the graft corresponding to the Valsalva sinus is cut using our original template (Fig. 10A). Commissure height and angle are symmetrically arranged using our original sizer (Fig. 10B $)^{50}$. Finally, the effective height of each cusp is adjusted to the same level. We hope that these strategies for standardization will improve long-term durability of the repair and AVP will be adopted more widely.

\section{Aortoscopy}

Assessment of post-repair cusp configuration is sometimes difficult under unpressurized conditions. Indeed, Sievers clearly demonstrated that the irregular leaflet appearance in the absence of diastolic pressure could be restored with normal diastolic pressure (Fig. 11) ${ }^{52}$. This may be one reason why AVP is limited to experts. In 1997, Itoh et al. applied endoscopy to evaluate cusp geometry before and after AVP under physiological (pressurized) conditions, and reported the usefulness of this strategy ${ }^{53}$. The Essen group revived this procedure in 2014 and confirmed the consistency with transesophageal echocardiographic findings ${ }^{54}$. Okita and colleagues observed the valve from the left ventricular side using a flexible videoscope, but they could not clarify the etiology of the failure ${ }^{55}$.

We have used aortoscopy since December 2015 in over 90 cases undergoing both VSRR and isolated AVP ${ }^{56}$. Although it prolongs the procedure time up to 20 - 30 minutes, AVP has become more sophisticated and reproducible with less residual AR than before the introduction of aortoscopy. The only drawback is the use of a non-negligible amount of crystalloid cardioplegic solution that should be minimized to prevent hemodilution. 


\section{Closing remarks}

In summary, the clinical course of patients with AR is suboptimal. AVP has attracted a great deal of attention as both mechanical and biological AVR have major disadvantages. Nonetheless, AVP has not been widely adopted due to the complexity of its technique and assessment. Due to recent technical and theoretical advances, AVP is anticipated to be increasingly performed with better outcomes. A number of prospective multicenter studies, such as CAVIAAR ${ }^{45}$, AVIATOR ${ }^{27}$, and Japanese Registry (UMIN000016145), are currently underway and will clarify the actual role of AVP in surgical treatment of AR in the near future.

\section{Conflict of interest}

The author declares that he has no conflicts of interest.

\section{Author contribution}

The author contributed to the design, interpretation of studies, drafting, revising, and approval of the manuscript.

\section{ORCID}

Takashi Kunihara:http://orcid.org/0000-0001-6903-6501

\section{References}

1. Tornos MP, Olona M, Permanyer-Miralda G, et al. Clinical outcome of severe asymptomatic chronic aortic regurgitation: a long-term prospective follow-up study. Am Heart J. 1995;130:333-9.

2. Detaint D, Messika-Zeitoun D, Maalouf J, et al. Quantitative echocardiographic determinants of clinical outcome in asymptomatic patients with aortic regurgitation: a prospective study. J Am Coll Cardiol Img. 2008;1:1-11.

3. Mentias A, Feng K, Alashi A, et al. Long-term outcomes in patients with aortic regurgitation and preserved left ventricular ejection fraction. J Am Coll Cardiol. 2016;68:2144-53.

4. Zoghbi WA, Enriquez-Sarano M, Foster E, et al. Recommendations for evaluation of the severity of native valvular regurgitation with two dimensional and Doppler echocardiography. J Am Soc Echocardiogr. 2003;16:777-802.

5. Etnel JRG, Huygens SA, Grashuis P, et al. Bioprosthetic aortic valve replacement in nonelderly adults: a systematic review, meta-analysis, microsimulation. Circ Cardiovasc Qual Outcomes. 2019;12:e005481.

6. Benedetto U, Melina G, Takkenberg JJ, Roscitano A, Angeloni E, Sinatra R. Surgical management of aortic root disease in Marfan syndrome: a systematic review and meta-analysis. Heart 2011;97:955-8.

7. Ouzounian M, Rao V, Manlhiot C, et al. Valve-sparing root replacement compared with composite valve graft procedures in patients with aortic root dilation. J Am Coll Cardiol. 2016;68:1838-47.

8. de Meester C, Pasquet A, Gerber BL, et al. Valve repair improves the outcome of surgery for chronic severe aortic regurgitation: a propensity score analysis. J Thorac Cardiovasc Surg. 2014;148:1913-20.

9. Iung B, Baron G, Butchart EG, et al. A prospective survey of patients with valvular heart disease in Europe: The Euro Heart Survey on Valvular Heart Disease. Eur Heart J. 2003;24: 1231-43.

10. Arimura S, Seki M, Sasaki K, et al. A nationwide survey of aortic valve surgery in Japan: current status of valve preservation in cases with aortic regurgitation. Gen Thorac Cardiovasc Surg. 2017;65:429-34.

11. Stamou SC, Williams ML, Gunn TM, Hagberg RC, Lobdell KW, Kouchoukos NT. Aortic root surgery in the United States: a report from the Society of Thoracic Surgeons database. J Thorac Cardiovasc Surg. 2015; 149:116-22.e4.

12. Kunihara T, Ichihara N, Miyata H, et al; Japan Cardiovascular Surgery Database. Valve-sparing root replacement and composite valve graft replacement in patients with aortic regurgitation: From the Japan Cardiovascular Surgery Database. J Thorac Cardiovasc Surg. 2019;158:1501-11.e6.

13. Nishimura RA, Otto CM, Bonow RO, et al. 2014 AHA/ACC guideline for the management of patients with valvular heart disease: a report of the American College of Cardiology/American Heart 
Association Task Force on Practice Guidelines. J Am Coll Cardiol 2014;63:e57-185.

14. Falk V, Baumgartner H, Bax JJ, et al; ESC Scientific Document Group. 2017 ESC/EACTS Guidelines for the management of valvular heart disease. Eur J Cardiothorac Surg. 2017;52:616-64.

15. Chaliki HP, Mohty D, Avierinos JF, et al. Outcomes after aortic valve replacement in patients with severe aortic regurgitation and markedly reduced left ventricular function. Circulation. 2002;106:268793.

16. Klodas E, Enriquez-Sarano M, Tajik AJ, Mullany CJ, Bailey KR, Seward JB. Optimizing timing of surgical correction in patients with severe aortic regurgitation: role of symptoms. J Am Coll Cardiol. 1997;30:746-52.

17. Brown ML, Schaff HV, Suri RM, Li Z, Sundt TM, Dearani JA. Indexed left ventricular dimensions best predict survival after aortic valve replacement in patients with aortic valve regurgitation. Ann Thorac Surg. 2009;87:1170-5.

18. Wang Y, Shi J, Li F, Wang Y, Dong N. Aortic valve replacement for severe aortic regurgitation in asymptomatic patients with normal ejection fraction and severe left ventricular dilatation. Interact Cardiovasc Thorac Surg. 2016;22:425-30.

19. Tornos P, Sambola A, Permanyer-Miralda G, Evangelista A, Gomez Z, Soler-Soler J. Long-term outcome of surgically treated aortic regurgitation: influence of guideline adherence toward early surgery. J Am Coll Cardiol. 2006;47:1012-7.

20. Kunihara T. Aortic valve repair for aortic regurgitation and preoperative echocardiographic assessment. J Med Ultrason (2001). 2019;46:51-62.

21. Malas T, Saczkowski R, Sohmer B, et al. Is aortic valve repair reproducible? analysis of the learning curve for aortic valve repair. Can J Cardiol. 2015;31:1497.e15-22.

22. Boodhwani M, de Kerchove L, Glineur D, et al. Repair-oriented classification of aortic insufficiency: impact on surgical techniques and clinical outcomes. J Thorac Cardiovasc Surg. 2009;137:286-94.

23. Berrebi A, Monin JL, Lansac E. Systematic echocardiographic assessment of aortic regurgitation-what should the surgeon know for aortic valve repair? Ann Cardiothorac Surg. 2019;8:331-41.

24. Sievers HH, Schmidtke C. A classification system for the bicuspid aortic valve from 304 surgical specimens. J Thorac Cardiovasc Surg. 2007;133:1226-33.

25. de Kerchove L, Mastrobuoni S, Froede L, et al. Variability of repairable bicuspid aortic valve phenotypes: towards an anatomical and repair-oriented classification. Eur J Cardiothorac Surg. 2019 Feb 20. pii: ezz033. doi: 10.1093/ejcts/ezz033. [Epub ahead of print]

26. Schafers HJ, Bierbach B, Aicher D. A new approach to the assessment of aortic cusp geometry. J Thorac Cardiovasc Surg. 2006;132:436-8.

27. Lansac E, Di Centa I, Sleilaty G, et al. Remodeling root repair with an external aortic ring annuloplasty. J Thorac Cardiovasc Surg. 2017;153:1033-42.

28. Schafers HJ, Schmied W, Marom G, Aicher D. Cusp height in aortic valves. J Thorac Cardiovasc Surg. 2013;146:269-74.

29. Komiya T, Shimamoto T, Nonaka M, Matsuo T. Is small cusp size a limitation for aortic valve repair?. Eur J Cardiothorac Surg. 2019;56:497-502.

30. Taylor WJ, Thrower WB, Black H, Harken DE. The surgical correction of aortic insufficiency by circumclusion. J Thorac Surg. 1958;35:192-205.

31. Cabrol C, Cabrol A, Guiraudon G, Bertrand M. Treatment of aortic insufficiency by means of aortic annuloplasty. Arch Mal Coeur Vaiss. 1966;59:1305-12.

32. de Kerchove L, Boodhwani M, Glineur D, et al. Valve sparing-root replacement with the reimplantation technique to increase the durability of bicuspid aortic valve repair. J Thorac Cardiovasc Surg. 2011;142:1430-8.

33. Schneider U, Aicher D, Miura Y, Schafers HJ. Suture annuloplasty in aortic valve repair. Ann Thorac Surg. 2016;101:783-5.

34. Rankin JS, Beavan LA, Cohn WE. Technique for aortic valve annuloplasty using an intra-annular "hemispherical" frame. J Thorac Cardiovasc Surg. 2011;142:933-6.

35. Kunihara T. Annular management during aortic valve repair: a systematic review. Gen Thorac Car- 
diovasc Surg. 2016;64:63-71.

36. David TE, Feindel CM. An aortic-valve sparing operation for patients with aortic incompetence and aneurysm of the ascending aorta. J Thorac Cardiovasc Surg. 1992;103:617-22.

37. Sarsam MA, Yacoub M. Remodeling of the aortic anulus. J Thorac Cardiovasc Surg. 1993;105:435-8.

38. Kunihara T. Valve-sparing aortic root surgery. CON: remodeling. Gen Thorac Cardiovasc Surg. 2019;67:82-92.

39. De Paulis R. PRO-CON debate: valve sparing aortic root surgery. PRO: reimplantation. Gen Thorac Cardiovasc Surg. 2019;67:77-81.

40. Shimizu H, Yozu R. Valve-sparing aortic root replacement. Ann Thorac Cardiovasc Surg. 2011;17:3306.

41. De Paulis R, Chirichilli I, Scaffa R, et al. Long-term results of the valve reimplantation technique using a graft with sinuses. J Thorac Cardiovasc Surg. 2016;151:112-9.

42. Schafers HJ, Raddatz A, Schmied W, et al. Reexamining remodeling. J Thorac Cardiovasc Surg. 2015;149:S30-6.

43. De Paulis R, De Matteis GM, Nardi P, Scaffa R, Buratta MM, Chiariello L. Opening and closing characteristics of the aortic valve after valve-sparing procedures using a new aortic root conduit. Ann Thorac Surg. 2001;72:487-94.

44. Lansac E, Di Centa I, Sleilaty G, et al. An aortic ring to standardise aortic valve repair: preliminary results of a prospective multicentric cohort of 144 patients. Eur J Cardiothorac Surg. 2010;38:147-54.

45. Lansac E, Bouchot O, Arnaud Crozat E, et al. Standardized approach to valve repair using an expansible aortic ring versus mechanical Bentall: early outcomes of the CAVIAAR multicentric prospective cohort study. J Thorac Cardiovasc Surg. 2015;149:S37-45.

46. Zakkar M, Bruno VD, Zacek P, et al. Isolated aortic insufficiency valve repair with external ring annuloplasty: a standardized approach. Eur J Cardiothorac Surg. 2020;57:308-16.

47. Kunihara T. Anatomy of the aortic root: implications for aortic root reconstruction. Gen Thorac Cardiovasc Surg. 2017;65:488-99.

48. Bierbach BO, Aicher D, Issa OA, et al. Aortic root and cusp configuration determine aortic valve function. Eur J Cardiothorac Surg. 2010;38:400-6.

49. de Kerchove L, Boodhwani M, Glineur D, Noirhomme P, El Khoury G. A new simple and objective method for graft sizing in valve-sparing root replacement using the reimplantation technique. Ann Thorac Surg. 2011;92:749-51.

50. Kunihara T. Toward standardization of valve-sparing root replacement and annuloplasty. Gen Thorac Cardiovasc Surg. 2018;66:685-91.

51. Capps SB, Elkins RC, Fronk DM. Body surface area as a predictor of aortic and pulmonary valve diameter. J Thorac Cardiovasc Surg. 2000;119:975-82.

52. Sievers HH. Better seeing is more believing: Angioscopy in aortic valve repair. J Thorac Cardiovasc Surg. 2015;149:1668-9.

53. Itoh T, Ohtsubo S, Furukawa K, Norita H. Aortic root endoscopy in valve-sparing operations. J Thorac Cardiovasc Surg. 1997;114:141-2.

54. Tsagakis K, Benedik J, El Khoury G, Jakob H. Aortic valve repair: Intraoperative evaluation of valve geometry by angioscopy. J Thorac Cardiovasc Surg. 2015;149:1666-8.

55. Okita Y, Oka T, Miyahara S, Okada K. Direct visualization of the aortic cusp from the left ventricle during aortic root reimplantation. J Thorac Cardiovasc Surg. 2012;144:981-2.

56. Kunihara T. Aortoscopy to evaluate cusp configuration after aortic valvuloplasty. In: Kunihara T, Takanashi S, editors. Aortic valve preservation, concepts and approaches. Tokyo: Springer; 2019. P. 53-6. 


\section{Figure legends}

Fig. 1. Long-term outcomes in patients with grade [?] III chronic aortic regurgitation and preserved left ventricular ejection fraction with or without aortic valve (AV) surgery (Reproduced with permission from reference 3$)$.

LVEF, left ventricular ejection fraction

Fig. 2. A: Long-term survival in patients undergoing aortic valve (AV) repair (solid line) or aortic valve replacement (AVR: 29 biological prostheses; 15 mechanical prosthesis) (dashed line). The dotted line shows the survival of an age- and gender-matched Belgian population (Reproduced with permission from reference 8).

B: Freedom from all-cause mortality in patients undergoing elective aortic root surgery by aortic valvesparing (AVS) technique and using bioprosthetic composite valve graft (bio-CVG) or mechanical composite valve graft (m-CVG) (Reproduced with permission from reference 7 ).

Fig. 3. A: Freedom from aortic valve reoperations in patients undergoing aortic valve (AV) repair (solid line) or aortic valve replacement (AVR) (dashed line) (Reproduced with permission from reference 8).

B: Prevalence of aortic valve reoperation over time using competing risk methods in patients undergoing elective aortic root surgery by aortic valve-sparing (AVS) technique and using bioprosthetic composite valve graft (bio-CVG) or mechanical composite valve graft (m-CVG) (Reproduced with permission from reference $7)$.

Fig. 4. A: Survival after aortic valve replacement adjusted for age and stratified by left ventricular indexed end-systolic dimensions (LVESD) (Reproduced with permission from reference 17).

B: Survival comparison among subgroups: $50 \%$ [?] LVEF < 55\% group vs. LVEF [?] $55 \%$ group (Reproduced with permission from reference 18).

LVEF, left ventricular ejection fraction

Fig. 5. Repair-oriented functional classification of aortic insufficiency (AI) with description of disease mechanisms and repair techniques used (Reproduced with permission from reference 22).

FAA, functional aortic annulus; STJ, sinotubular junction; SCA, subcommissural annuloplasty

Fig. 6. A: Schematic representation of the system for classification of the bicuspid aortic valves. Prominent lines in schematic drawings represent raphe (Reproduced with permission from reference 24).

B: Schematic illustrations of the three groups of phenotypes of the repair-oriented bicuspid aortic valve classification (Reproduced with permission from reference 25).

Fig. 7. A: Schematic drawing of the aortic valve and root.

STJ, sinotubular junction; VAJ, ventriculoaortic junction; GH, geometric height;

eH, effective height.

B: Intraoperative photograph showing measurement of the effective height of the noncoronary cusp of a bicuspid aortic valve with the caliper (Both reproduced with permission from reference 26).

Fig. 8. Schematic drawing of external suture annuloplasty (A), external ring annuloplasty (B), and internal ring annuloplasty (C) (Reproduced with permission from reference 33, 27, and 34, respectively).

Fig. 9. Schematic drawing of the aortic root remodeling technique (A) and the aortic valve reimplantation technique (B) (Reproduced with permission from reference 40).

Fig. 10. A: Our original template to cut each scallop of the graft corresponding to the Valsalva sinus. 
B: Our originally developed sizer with various sizes $(16-30 \mathrm{~mm}$ ) (a) with six equally distributed grooves facilitating marking of the middle points (b) (Reproduced with permission from reference 50).

Fig. 11. Endoscopic view of the normal aortic root at different diastolic pressures. A, $80 \mathrm{mmHg}$; B, 40 $\mathrm{mmHg}$; C, $0 \mathrm{mmHg}$ (Reproduced with permission from reference 52).

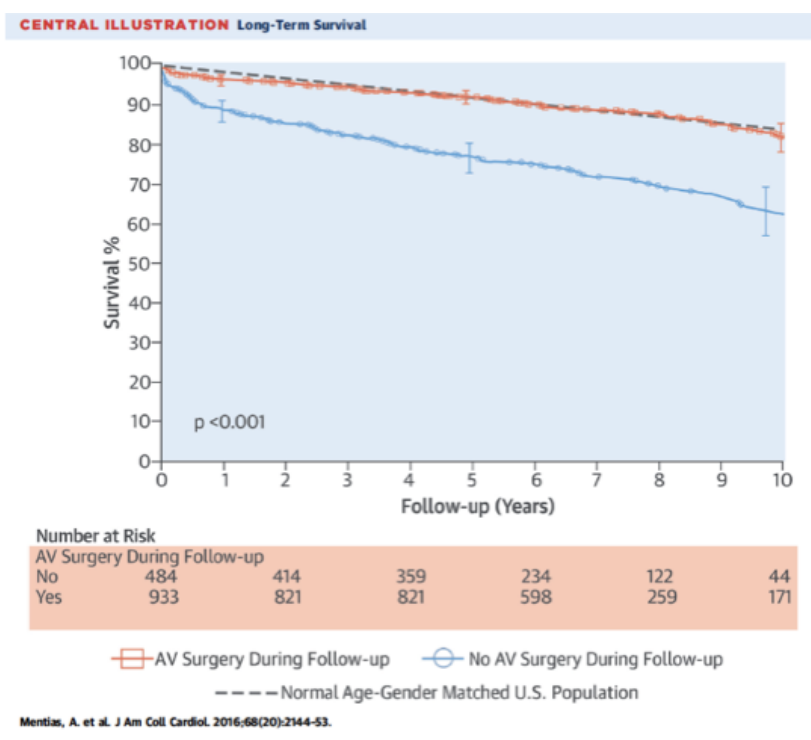

Fig 1
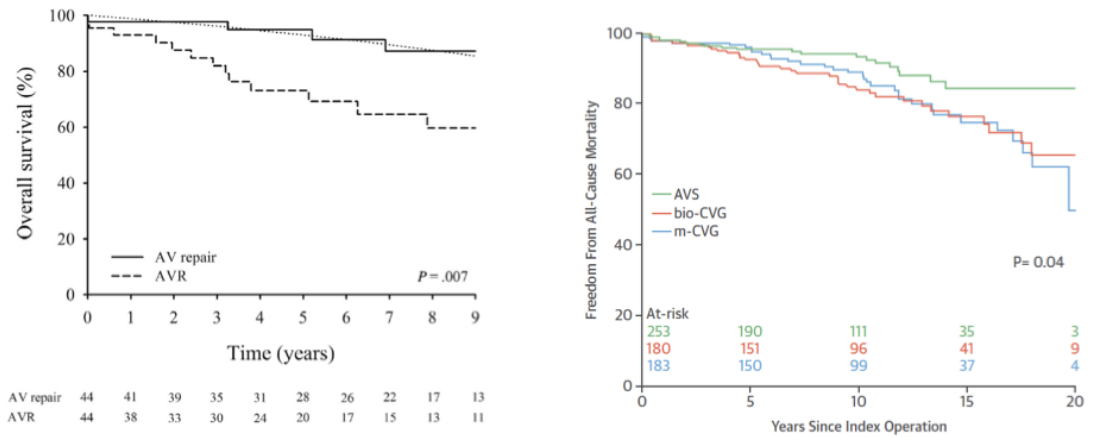

A

B

Fig 2 


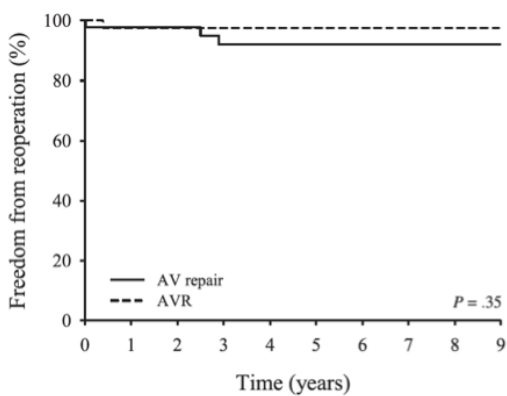

$\begin{array}{lllllllllll}\text { AV repair } & 44 & 41 & 38 & 32 & 28 & 25 & 23 & 22 & 14 & 10 \\ \text { AVR } & 44 & 37 & 32 & 29 & 23 & 20 & 17 & 15 & 13 & 12\end{array}$

A

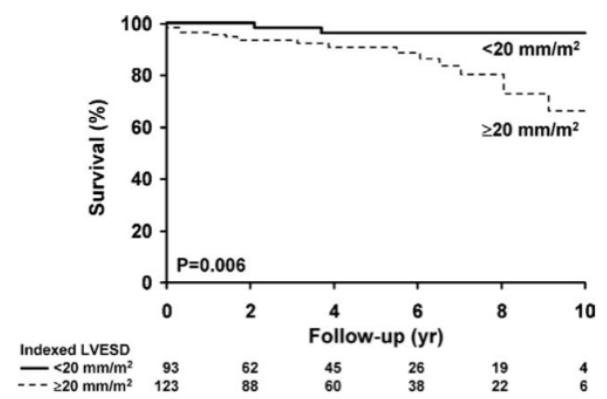

A

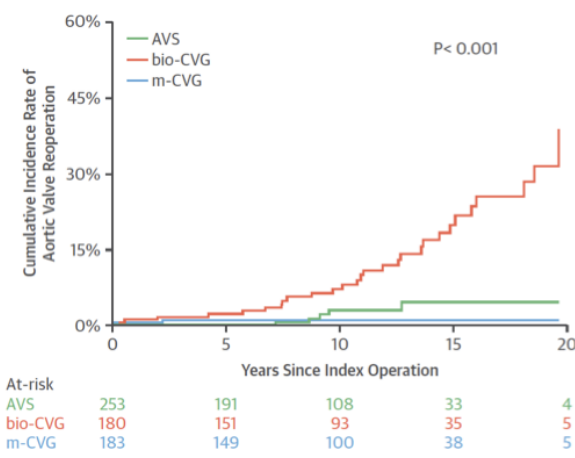

B

Fig 3

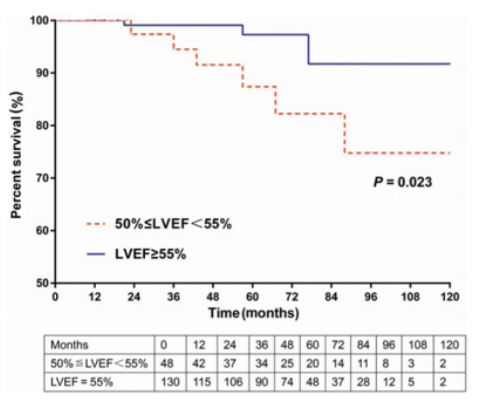

B

Fig 4 


\begin{tabular}{|c|c|c|c|c|c|c|}
\hline \multirow{2}{*}{ Al Class } & \multicolumn{4}{|c|}{$\begin{array}{c}\text { Type I } \\
\text { Normal cusp motion with FAA dilatation or cusp perforation }\end{array}$} & \multirow{2}{*}{$\begin{array}{c}\text { Type II } \\
\text { Cusp } \\
\text { Prolapse }\end{array}$} & \multirow{2}{*}{$\begin{array}{c}\text { Type III } \\
\text { Cusp } \\
\text { Restriction }\end{array}$} \\
\hline & la & $\mathrm{lb}$ & Ic & Id & & \\
\hline Mechanism & & & & & & \\
\hline $\begin{array}{c}\text { Repair } \\
\text { Techniques } \\
\text { (Primary) }\end{array}$ & $\begin{array}{c}\text { STJ } \\
\text { remodeling } \\
\text { Ascending } \\
\text { aortic graft }\end{array}$ & $\begin{array}{l}\text { Aortic Valve } \\
\text { sparing: } \\
\text { Reimplantation } \\
\text { or } \\
\text { Remodeling } \\
\text { with SCA }\end{array}$ & SCA & $\begin{array}{c}\text { Patch } \\
\text { Repair } \\
\text { Autologous or } \\
\text { bovine } \\
\text { pericardium }\end{array}$ & $\begin{array}{l}\text { Prolapse } \\
\text { Repair } \\
\text { Plication } \\
\text { Triangular } \\
\text { resection } \\
\text { Free margin } \\
\text { Resuspension } \\
\text { Patch }\end{array}$ & $\begin{array}{c}\text { Leaflet } \\
\text { Repair } \\
\text { Shaving } \\
\text { Decalcificatio } \\
\text { Patch }\end{array}$ \\
\hline (Secondary) & SCA & & $\begin{array}{c}\text { STJ } \\
\text { Annuloplasty }\end{array}$ & SCA & SCA & SCA \\
\hline
\end{tabular}

Fig 5

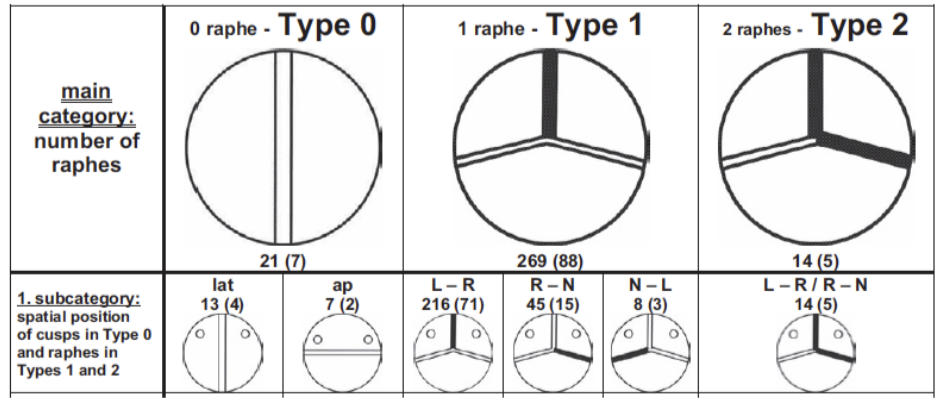

Type A

Type B

Type C

Symmetrical Asymmetrical

B
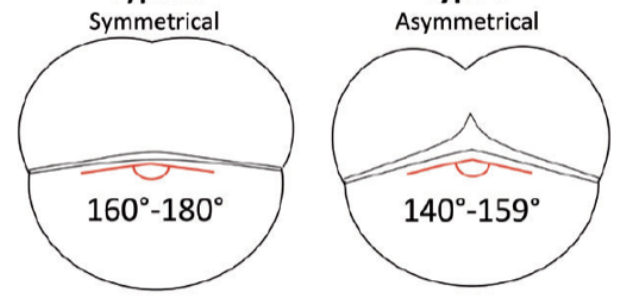

Very Asymmetrical

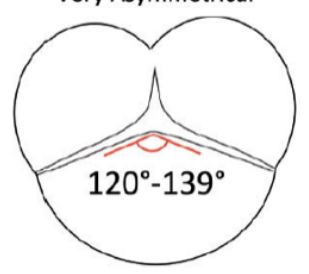

Fig 6 


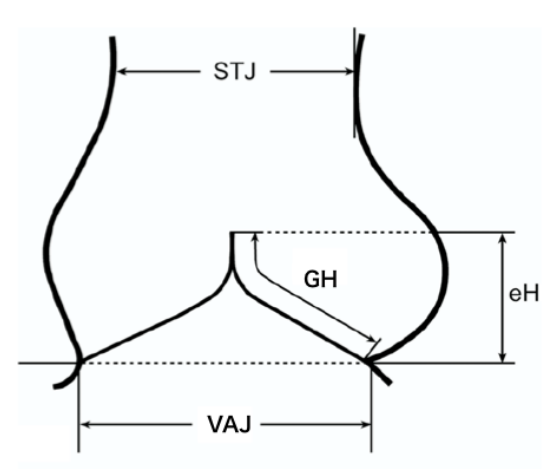

A

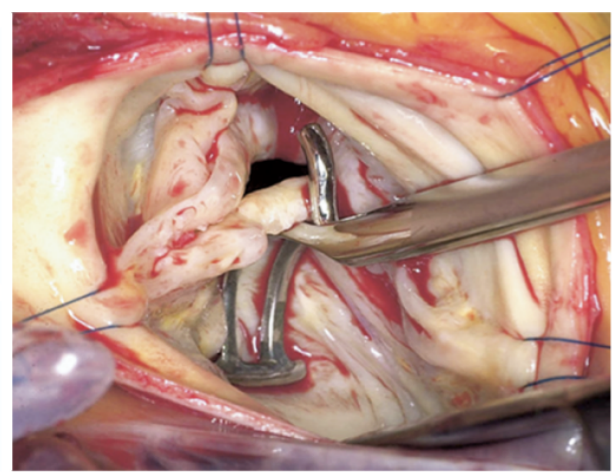

B

Fig 7

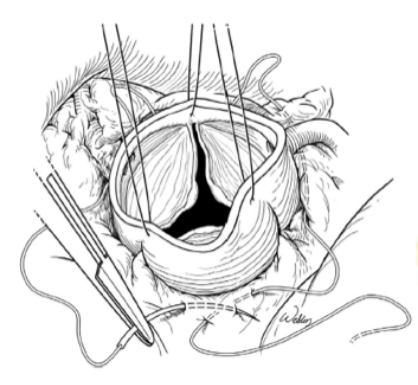

A

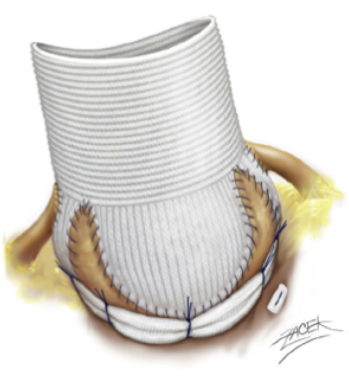

B

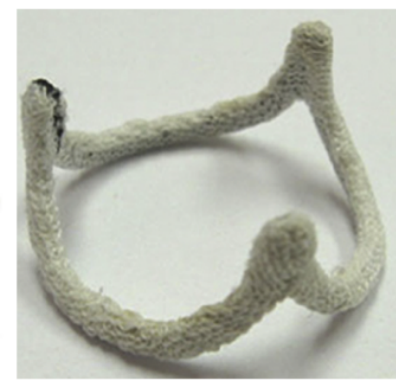

C

Fig 8

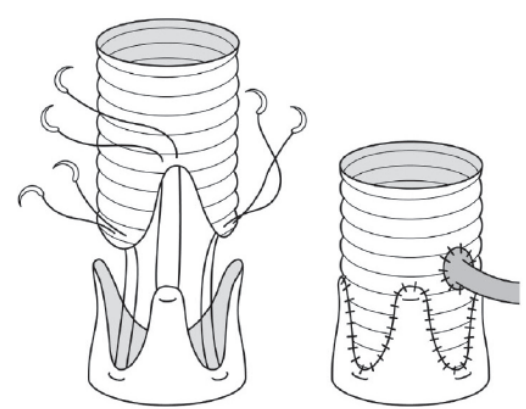

Aortic root remodeling

A

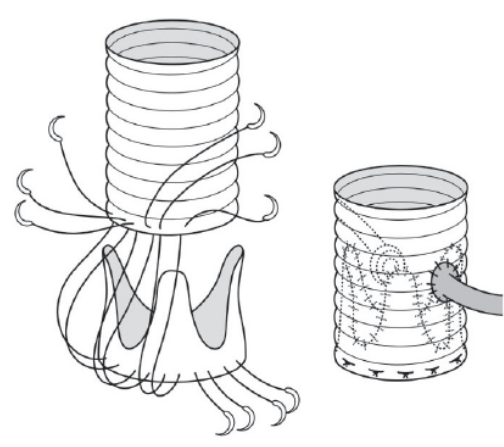

Aortic valve reimplantation

B

Fig 9 


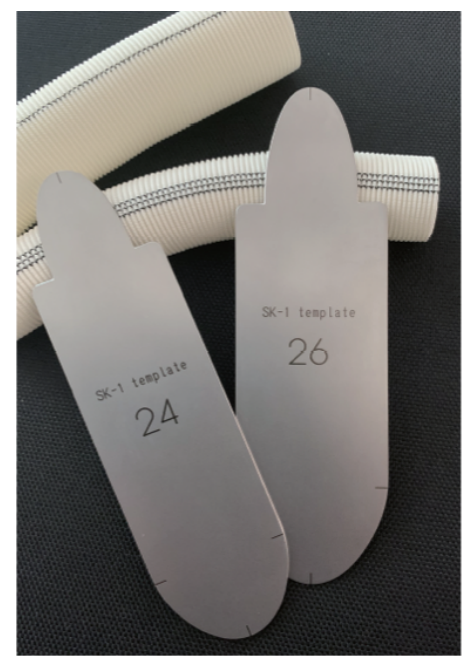

A

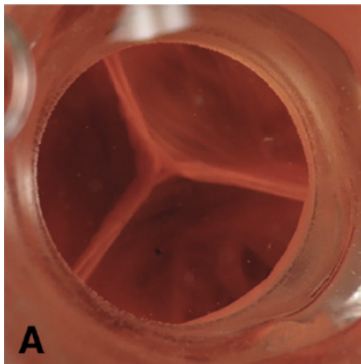

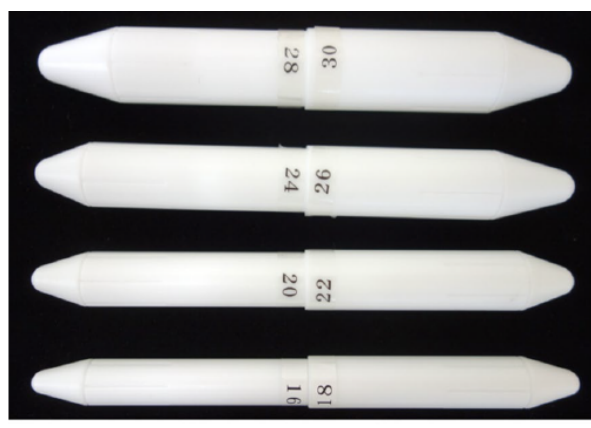

(a)

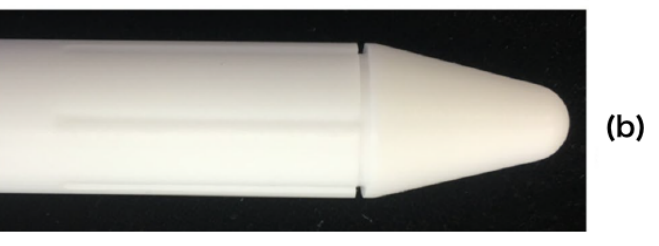

B

Fig 10
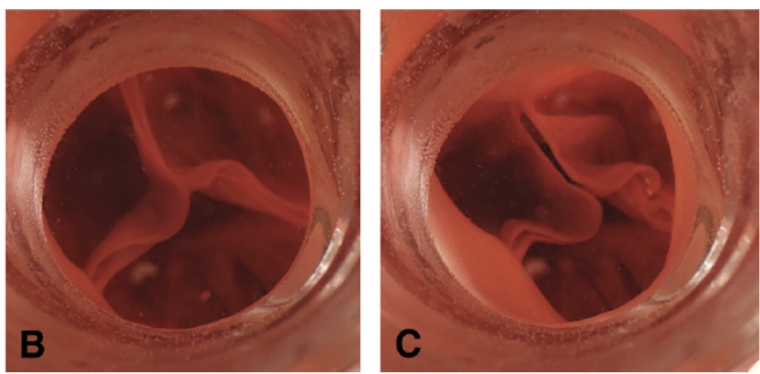

Fig 11 